\title{
Energy saving in the formation of covered courtyards
}

\author{
Andrey Rymarov ${ }^{1, *}$ \\ ${ }^{1}$ National Research University Moscow State University of Civil Engineering, 129337, Yaroslavskoye \\ Shosse, 26, Moscow, Russia
}

\begin{abstract}
In the city in the winter going outside the house you find yourself in a slippery and snowy weather with frosts and wind of different intensity. Forming covered with translucent roofs courtyards and streets can improve the quality of life of citizens. At the same time, in summer, at elevated outdoor temperatures, it is possible to create the required microclimate for people by blocking yards and streets and adding engineering systems that form the microclimate. Transport should be removed from such yards and streets, except for electric cars and bicycles, which will reduce the gas contamination and dust of these protected spaces. To form a year-round comfortable space for people in the covered yard, it is necessary to analyse the temperature regime. The most difficult is the thermal regime of the covered yard in the warm period of the year, when the heat flow from solar radiation in conjunction with the high temperatures of the outside air form the temperature of the indoor air in the covered yard. Thermal behaviour of the covered courtyard during the warmer period of the year considered in this article.
\end{abstract}

\section{Introduction}

In Russia, there are not enough places for a comfortable stay outside of houses and other buildings, as it is always necessary to protect yourself from changeable and often adverse weather throughout the year. The cold period of the year is known for its frosts with wind, snowfall and ice-covered roads [1], and the warm period of the city due to global warming in recent decades in Russia can be formed very hot temperature conditions in the daytime.

Blocked yard or street, or part of the street translucent ceiling, allows throughout the year and in the warm period of the year to get more comfortable conditions for people outside the premises and buildings. Such blocked yards or streets can connect neighbourhoods with parks and transportation systems and other places and buildings in the city. And, such yards can form the potential of energy saving for heating systems and heat consumption.

\footnotetext{
*Corresponding author: rymarov@list.ru
} 


\section{Methods of calculating the thermal conditions}

Considered a residential building with a covered courtyard. When forming a covered yard, it is necessary to carry out calculations of its thermal regime to determine the dynamics of the change in the value of the internal air temperature in order to understand the level of comfort when a person is inside such a space.

In the warm period of the year, the flow of heat into the space of the covered yard occurs through the translucent overlap due to solar radiation and due to heat transfer, and when the air space of the covered yard is heated, the heat flows through the walls and Windows overlooking the courtyard will enter the premises of the building, warming them, and the heat flow will enter the ground of the blocked yard, increasing its temperature, which allows for calculations of the temperature regime in the closed yard. Passages to the courtyard through the arches should be closed with easily opened doors.

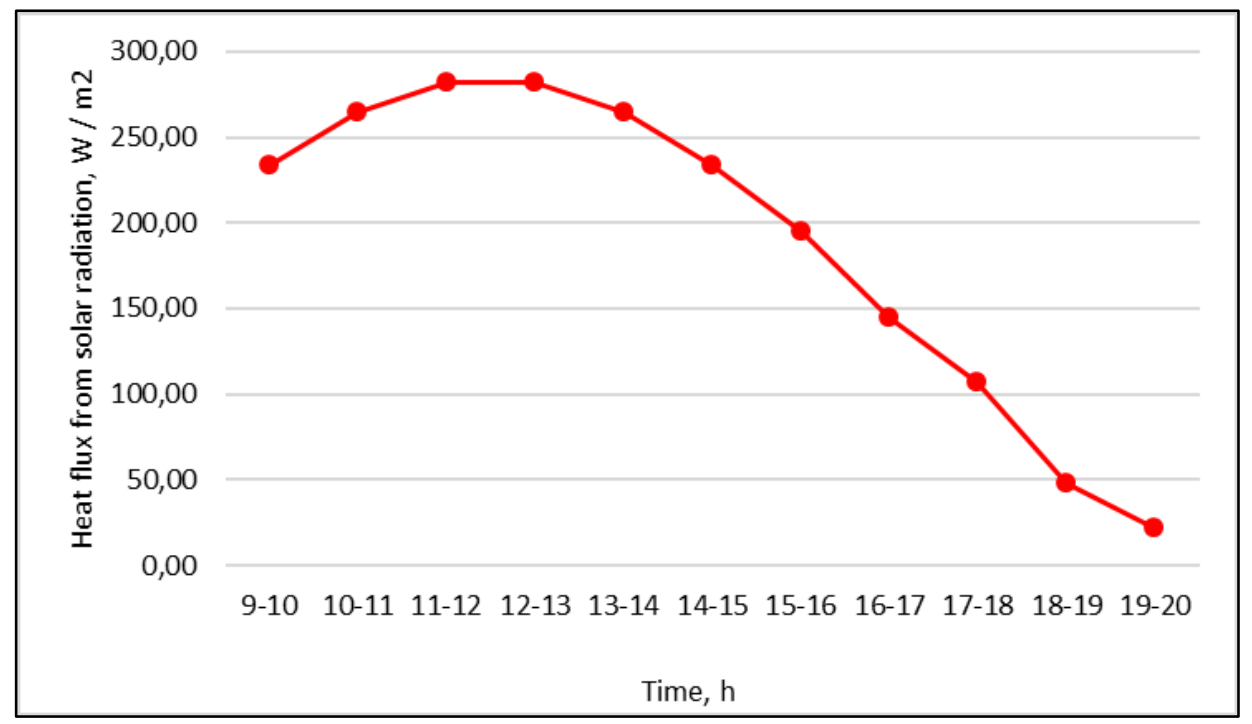

Fig. 1. Heat flux from solar radiation. 


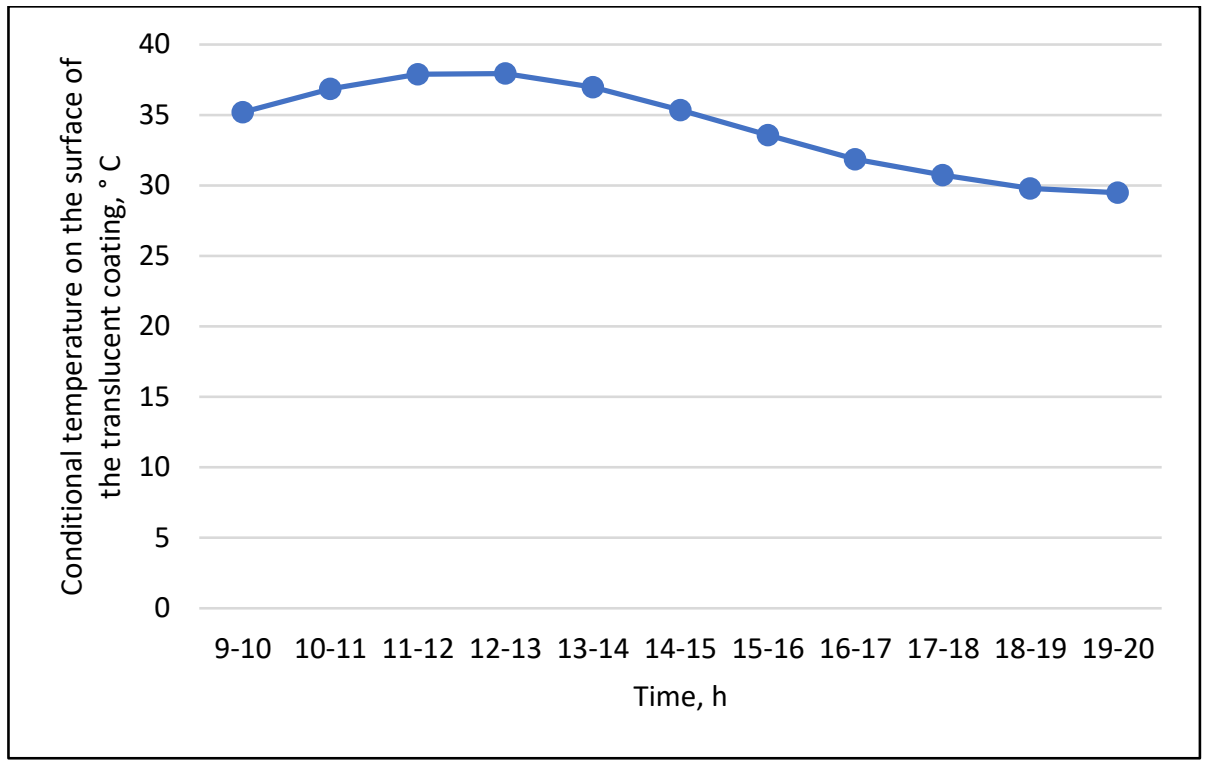

Fig. 2. Conditional temperature on the surface of the translucent coating for July.

Consider the thermal regime of the covered yard for a building located in the climatic conditions of the city of Moscow, which will allow us to understand how to manage its microclimate.

To analyse the thermal regime of the covered translucent roof of the courtyard in the warm period of the year, it is necessary to analyse the temperature change of the outside air in the warm period of the year, when the heat from solar radiation (figure 1) and the outside air temperature (figure 2 and 3 ) are maximum in the daytime.

Figure 1 shows how the heat flux from solar radiation entering the horizontal surface with a cloudless sky during the day from 9 to 20 hours, which is necessary to determine the heat flux coming through the translucent coating in the inner courtyard due to heat transfer and in the form of solar radiation on the walls, Windows and soil, warming them. The main source of heat input into the courtyard is heat from solar radiation, its value is determined based on existing climatic reference data, depending on the latitude and azimuth of the sun during the day. Based on data on heat fluxes from solar radiation, the calculations of the conditional temperature of the outside air at the surface of the translucent overlap during the daytime for July from 9 to 20 hours, and the results of the calculations are shown in figure 2 . 


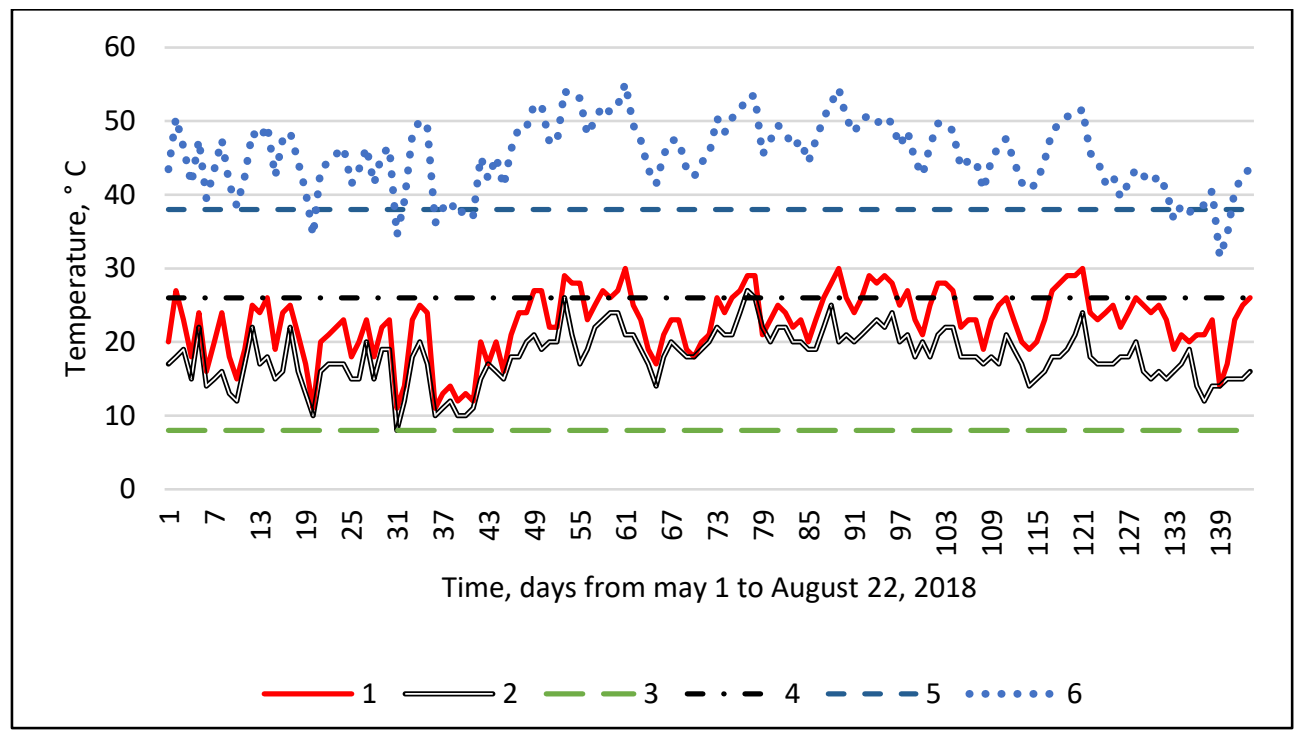

Fig. 3. Change in air temperature (o C) in time from May 1 to August 22, 2018: 1 - average daytime temperature, 2 - average night temperature, 3 - end temperature of the cold period of the year, 4 - temperature for calculations of air conditioning systems, 5 - maximum temperature for July, 6 - conditional temperature at the surface of the translucent structure for the horizontal surface.

The average temperature for day and night time is obtained according to the existing meteorological information. The temperature of $+8^{\circ} \mathrm{C}$ in comparison with the average values of day and night outside air temperature shows that this period is warm and heating systems do not work. The temperature for the calculation of the air conditioning system shows that its value does not consider the flow of heat from solar radiation. The maximum outside temperature is closer to the nominal outside temperature, which considers the heat input from solar radiation, but still below it. From the graph analysis in Fig. 3 it can be seen that the conditional temperature of the outside air at the surface of the translucent structure for the horizontal surface has a maximum value on the temperature regime of the covered translucent roof of the courtyard in the warm period of the year, and in interaction with the penetrating through the translucent coating of solar radiation determine the temperature of the internal air in the courtyard.

Temperature values from 1 to 5 according to figure 3 are taken based on the normative document SP 131.13330.2012 "Construction climatology", operating in the territory of the Russian Federation. The calculation of the conditional temperature at the horizontally located surface of the translucent roof (figures 2 and 3 ) is carried out based on the technique described in the Handbook for the design of buildings [3].

\section{Results of calculations}

If the courtyard is blocked by a translucent roof with non-opening doors, the courtyard will turn into a kind of atrium, which can and should be used, for example, by filling the atrium space, for example, a winter garden with the necessary microclimate for the winter and summer periods of the year [4].

The overlap of the courtyard should have opening doors, which will allow in the warm period of the year to regulate the thermal regime in the airspace of the courtyard. If in the warm period of the year the indoor courtyard with translucent ceiling to keep permanently closed, in the daytime it will be very hot, and at night it will cool. If in the evening, night and 
morning hours of the day to open the sash cover, the courtyard will be ventilated and cool after sunset naturally.

Consider a building with a courtyard, schematic section of the building is shown in figure 4. The plan of the building is shown in figure 5. Heat flows in the courtyard (incoming and outgoing) are shown in figures 4 and 5.

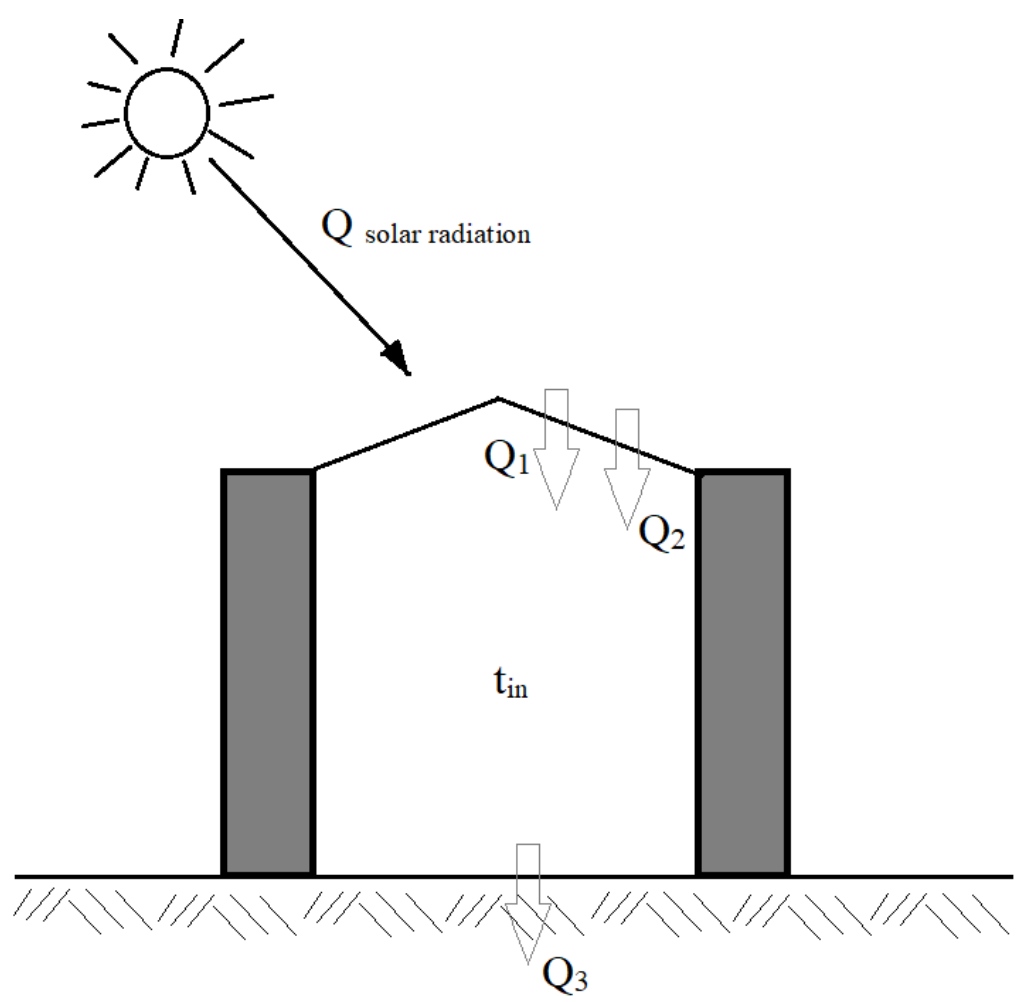

Fig. 4. The section of the building with the blocked yard with application of a translucent design.

To reduce the temperature of the air in the courtyard during the day, it is proposed to use an air-to-ground heat pump, which will cool the air in the courtyard space, directing the excess heat to the ground for accumulation, or an air-to-water heat pump, directing the excess heat to a heat-insulated water tank for accumulation. The accumulated heat can be used in the cold period of the year to heat the space of the courtyard, for the heating system, for hot water supply, etc. Figure 6 shows the heat pump application diagram. 


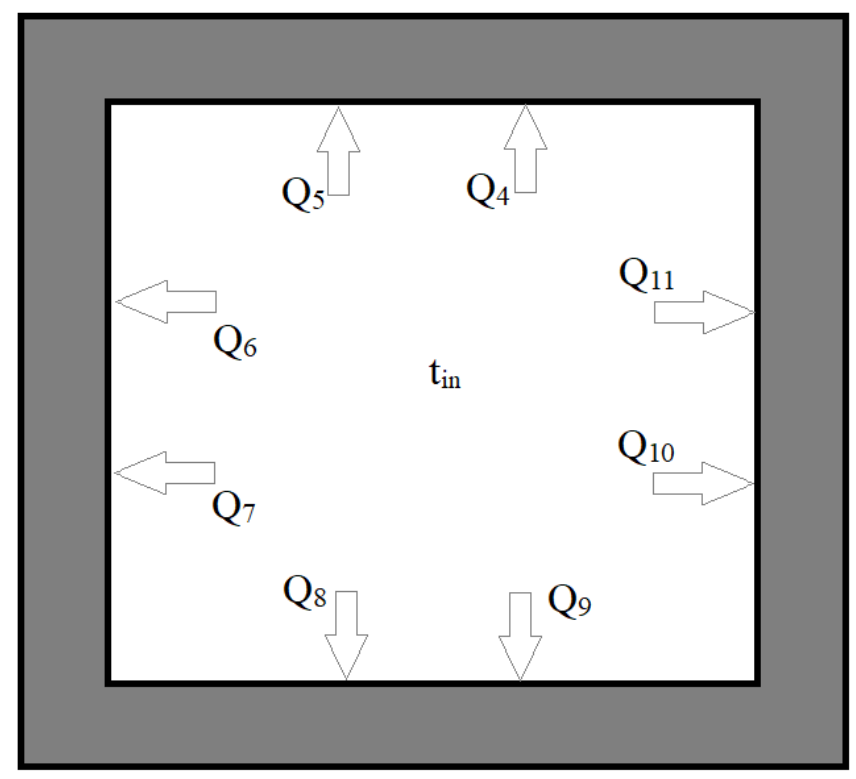

Fig. 5. The plan of the building with a blocked translucent design yard.

The covered yard is set with dimensions in the plan of $63 \times 63 \mathrm{~m}$ along the perimeter of the covered yard there is a building with the length of the external facades of $87 \mathrm{~m}$ and the number of floors 5. The total area of Windows and walls facing the courtyard is $840 \mathrm{~m}^{2}$ and $3393.6 \mathrm{~m}^{2}$, respectively, and the area of the roof and ground in the covered courtyard is $3960 \mathrm{~m}^{2}$. The volume of the covered yard is $213312 \mathrm{~m}^{3}$ [1].

According to the existing Russian Federation standards set of rules 50.13330.2012 "Thermal protection of buildings" and set of rules 131.13330.2012 "Construction climatology" derived heat transfer coefficients of Windows of $2.04 \mathrm{~W} /\left(\mathrm{m}^{2} \times{ }^{\circ} \mathrm{C}\right)$, walls of $0.33 \mathrm{~W} /\left(\mathrm{m}^{2} \times{ }^{\circ} \mathrm{C}\right)$ and the translucent roof of $2.78 \mathrm{~W} /\left(\mathrm{m}^{2} \times{ }^{\circ} \mathrm{C}\right)$.

We will accept as the assumption that in all building in day and night time the temperature in the rooms turned to the courtyard equal $+25^{\circ} \mathrm{C}$ at the expense of the working air conditioning system is maintained.

Heat flow in the daytime from the overlap enters the courtyard $\left(\mathrm{Q}_{1}\right.$ and $\left.\mathrm{Q}_{2}\right)$, and then when the temperature of the internal air in the courtyard increases, the heat flow enters the premises of the building through the Windows and walls $\left(\mathrm{Q}_{4}-\mathrm{Q}_{11}\right)$ and into the ground $\left(\mathrm{Q}_{3}\right)$, as shown in figures 4 and 5 .

At night, when there is no sun and the outside temperature drops, the courtyard begins to cool down and the heat flow begins to flow from the courtyard through the coating into the outside air. If necessary, you can open the sash cover and then the cooling process of the courtyard at night will increase.

When an air-to-ground or air-to-water heat pump is used, the excess heat from the courtyard air space $\left(\mathrm{Q}_{12}\right)$ moves throughout the day to the ground or water $\left(\mathrm{Q}_{13}\right)$ for accumulation and subsequent use (figure 6).

Balance equations of losses and heat inputs in the covered yard allow to determine the temperature of the internal air $(\mathrm{t})$.

$$
\begin{gathered}
Q_{1}+Q_{2}=Q_{3}+Q_{4}+\cdots+Q_{11} \\
f(t)=f\left(Q_{1} \ldots Q_{11}\right)
\end{gathered}
$$


The balance equations of heat loss and heat input in the covered yard, considering the action of the heat pump, are supplemented by the absorption of excess heat $\left(\mathrm{Q}_{12}\right)$ by the evaporator of the heat pump.

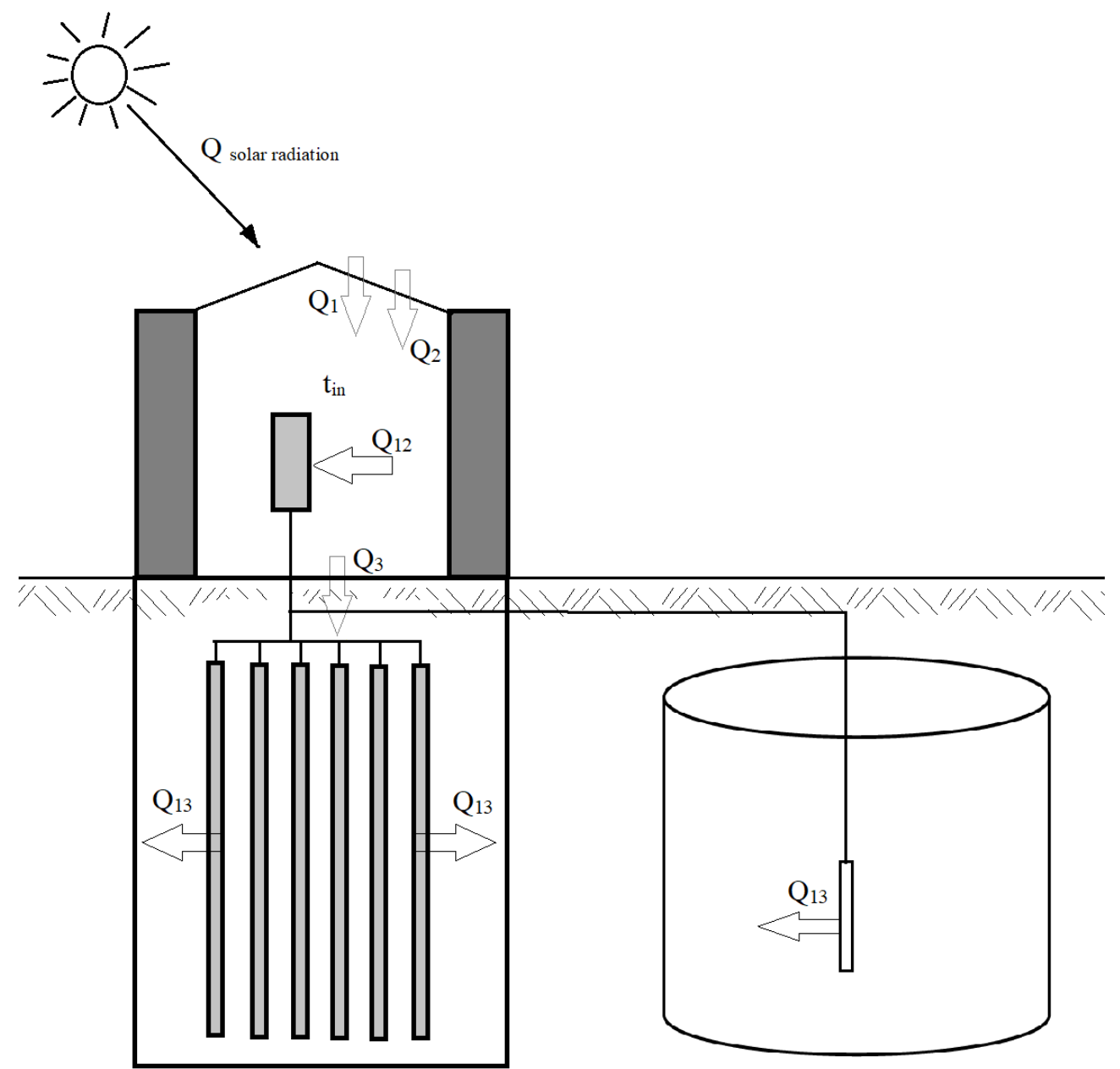

Fig. 6. The section of the building with the blocked translucent design the yard and with heat pumps of type air-ground and air-water.

The calculations showed that for the period from May 1 to August 22, 2018, the average value of the maximum amount of heat entering the courtyard during the day is $600 \mathrm{~kW}$, and the average value of the maximum air temperature is $70^{\circ} \mathrm{C}$. the Necessary temperature for a comfortable stay of people in the courtyard is taken to be $22-26^{\circ} \mathrm{C}$, which is approximately $45^{\circ} \mathrm{C}$ (figure 7) below the temperature in the courtyard. To use the soil as a heat energy storage device, it is necessary to simulate the thermal regime of the soil [5], which will determine the accumulating capacity and volume of the soil mass, as well as the depth and frequency of wells for the placement of capacitors and determine the required number and power of heat pumps. 


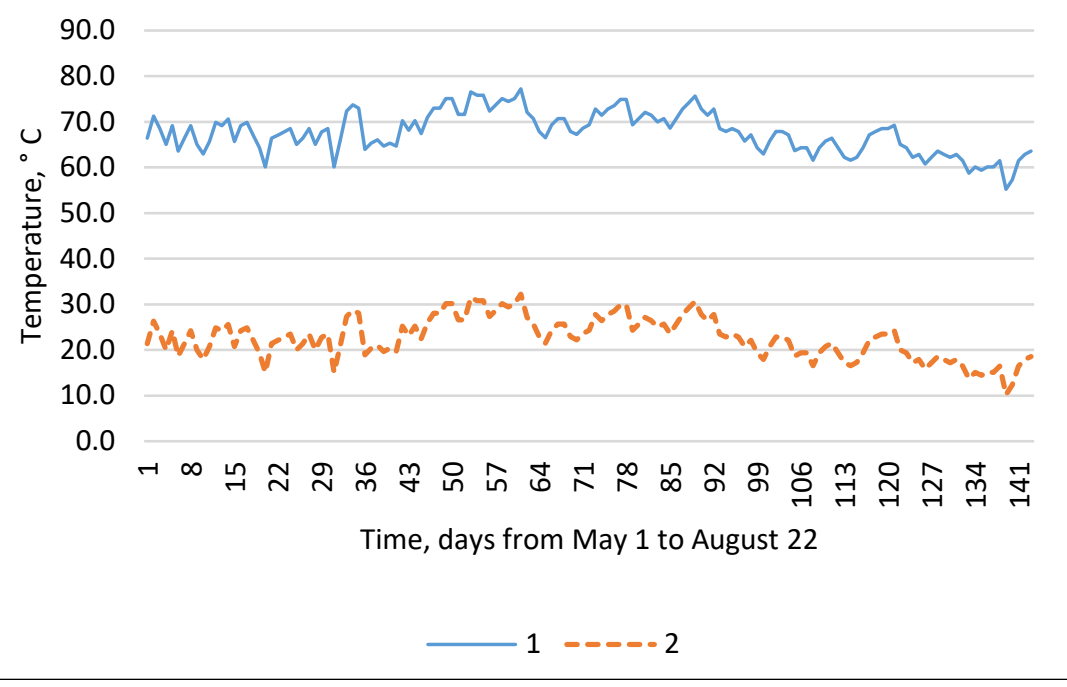

Fig. 7. Temperature change in the covered courtyard from May 1 to August 22, 2018 with the maximum value of heat coming from solar radiation (1) and the necessary temperature for a comfortable stay of a person in the courtyard (2).

The calculations are carried out for the temperature conditions of Moscow for the actual outdoor temperature values for the warm period of 2018 .

\section{Conclusion}

The increased temperature in the indoor courtyard allows you to get a more comfortable space for people to relax in the winter, and save thermal energy in the warm season, accumulating it in the ground or water for later use. Translucent coating obscures the space of the yard, which may require additional lighting [6], it is necessary to clean the glass from snow in winter and dust in the warm season. Ventilation of a large volume of the courtyard is necessary from the condition of the number of people who may rest or spend time in the considered space of the courtyard.

The saved thermal energy can be used for any kind of heating of the courtyard in winter and other tasks of heat consumption by the building, which will lead to energy saving, which improves the environment and allows to solve many infrastructure problems.

\section{References}

1. A. Rymarov, M. Razakov, The thermal mode of the covered yard (IOP Conf. Series: Earth and Environmental Science 177, 012025, 2018)

2. V. N. Bogoslovsky, Directory of the designer. Ventilation and air conditioning (Book 1, part 3, ed. N. Pavlov, Y. I. Schiller, Moscow, Stroyizdat, 319, 1992)

3. A. Rymarov, N. Parfenteva, K. Valančius, P. Sabina, M. Violeta, Journal of Environmental Engineering and Landscape Management, 26, 3, 195-201 (2018)

4. O. Brukhanov, A. Rymarov, A. Malysheva, D Titkov, MATEC Web of Conferences 5, Series "5th International Scientific Conference "Integration, Partnership and Innovation in Construction Science and Education", IPICSE 2016", 04028 (2016)

5. S. E. Gorgots, A. K. Solovyov, Lighting engineering, 2, 51-52 (2006) 